\title{
Supercapacitor-based energy management for future aircraft systems
}

DOI:

10.1109/APEC.2010.5433398

Link to publication record in Manchester Research Explorer

\section{Citation for published version (APA):}

Todd, R., Wu, D., Dos Santos Girio, J. A., Poucand, M., \& Forsyth, A. J. (2010). Supercapacitor-based energy management for future aircraft systems. In Conference Proceedings - IEEE Applied Power Electronics Conference and Exposition - APEC/Conf Proc IEEE Appl Power Electron Conf Expo APEC (pp. 1306-1312) https://doi.org/10.1109/APEC.2010.5433398

Published in:

Conference Proceedings - IEEE Applied Power Electronics Conference and Exposition - APEC|Conf Proc IEEE Appl Power Electron Conf Expo APEC

\section{Citing this paper}

Please note that where the full-text provided on Manchester Research Explorer is the Author Accepted Manuscript or Proof version this may differ from the final Published version. If citing, it is advised that you check and use the publisher's definitive version.

\section{General rights}

Copyright and moral rights for the publications made accessible in the Research Explorer are retained by the authors and/or other copyright owners and it is a condition of accessing publications that users recognise and abide by the legal requirements associated with these rights.

\section{Takedown policy}

If you believe that this document breaches copyright please refer to the University of Manchester's Takedown Procedures [http://man.ac.uk/04Y6Bo] or contact uml.scholarlycommunications@manchester.ac.uk providing relevant details, so we can investigate your claim.

\section{OPEN ACCESS}


This paper was published at the IEEE Applied Power Electronics Conference and Exposition (APEC) in Feb. 2010, doi 10.1109/APEC.2010.5433398, and is available at:

http://ieeexplore.ieee.org/stamp/stamp.jsp?tp=\&arnumber=5433398

R. Todd, D. Wu, J.A. dos Santos Girio, M. Poucand, A.J. Forsyth, "Supercapacitor-based energy management for future aircraft systems," IEEE Applied Power Electronics Conference and Exposition (APEC), pp.1306-1312, 21-25 Feb. 2010, doi: 10.1109/APEC.2010.5433398

(C) 2014 IEEE. Personal use of this material is permitted. Permission from the IEEE must be obtained for all other uses, in any current or future media, including reprinting/republishing this material for advertising or promotional purposes, creating new collective works, for resale or redistribution to servers or lists, or reuse of any copyrighted component of this work in other works. 


\title{
Supercapacitor-Based Energy Management for Future Aircraft Systems
}

\author{
R. Todd, D. Wu, J.A. dos Santos Girio, M. Poucand, A.J. Forsyth \\ Rolls-Royce UTC \\ School of Electrical \& Electronic Engineering \\ The University of Manchester, UK \\ rebecca.todd@manchester.ac.uk
}

\begin{abstract}
A power-based control method is proposed and analysed for a supercapacitor energy storage device. The performance of the energy storage device is examined by simulation and experimentally when operating on a high voltage DC bus with a multi-phase, fault-tolerant generator and a high power, pulsed load such as an actuation or avionic system. In the practical system the energy storage device is emulated using a bi-directional electronic load and a real-time simulation platform. The energy storage device is shown to minimise the DC bus transients and virtually eliminate the torque pulsation on the generator shaft. The system design and performance trade-offs are analysed. The experimental work uses a $70 \mathrm{~kW}$ generator and $30 \mathrm{~kW}$ programmable load emulation devices.
\end{abstract}

\section{SYMBOLS}

$\begin{array}{ll}C_{b u s} & \text { Combined filter capacitance on the DC bus } \\ D & \text { Duty-ratio } \\ I_{b u s} & \text { Total bus current } \\ I_{E S D} & \text { Energy storage device output current } \\ I_{g e n} & \text { Total generator current } \\ I_{L o a d} & \text { Load current of the active load system } \\ I_{s c} & \text { Current in the supercapacitor bank } \\ \tilde{I}_{s c} & I_{s c} \text { error }\left(I_{s c-L} I_{s c-r c} I_{s c}\right) \\ I_{s c-L} & \text { Supercapacitor load current demand } \\ I_{s c-r c} & \text { Supercapacitor recharge current demand } \\ k_{p} & I_{s c} \text { controller proportional gain } \\ k_{r c} & \text { Recharge control function } \\ L & \text { DC/DC converter inductor } \\ R_{E S R / E P R} & \text { Series resistance of supercapacitor / leakage losses } \\ T_{e} & \text { Torque } \\ T_{I} & I_{s c} \text { controller integral gain } \\ V_{E S D}{ }^{*} & \text { Control variable } \\ V_{s c} & \text { Overall terminal voltage of the supercapacitor bank } \\ V_{s c}{ }^{*} & \text { Reference value for } V_{s c} \\ V_{s c} & V_{s c} \text { error }\left(V_{s c}{ }^{*}-V_{s c}\right) \\ V_{s c 0} & \text { Initial value of } V_{s c}\end{array}$

\section{INTRODUCTION}

The increasing levels of electrically powered equipment on aircraft, especially highly dynamic loads such as electric actuators and advanced avionic systems, are placing

The authors would like to thank Rolls-Royce plc for promoting and funding the Intelligent Electrical Power Network Evaluation Facility (IEPNEF) which is housed at The University of Manchester in the School of Electrical and Electronic Engineering. IEPNEF has been developed to evaluate ultra-compact and intelligent electrical networks for aerospace, marine and energy applications. It is part of the Rolls-Royce University Technology Centre (UTC) for Electrical Systems in Extreme Environments within the Power Conversion Group. increasingly severe demands on the engine mounted generators. The problems are particularly acute on small platforms where the non-propulsive power taken from the engine is proportionately very high, and consequently there is a risk that rapid electrical load transients could result in an engine surge, which may compromise the mission objectives or cause catastrophic failure of the platform.

To mitigate these effects, this paper examines the use of a supercapacitor-based energy storage device (ESD) connected to the DC distribution bus of an experimental aircraft electrical system. Supercapacitors are used as the energy source owing to their power density and cyclability. The basic configuration of the system is illustrated in Fig. 1, which shows a five-phase, fault-tolerant engine-embedded generator [1] supplying a high voltage DC bus; the main elements on the bus are the ESD, a generic dynamic load representing an actuator or a high power avionic system, and a background load.

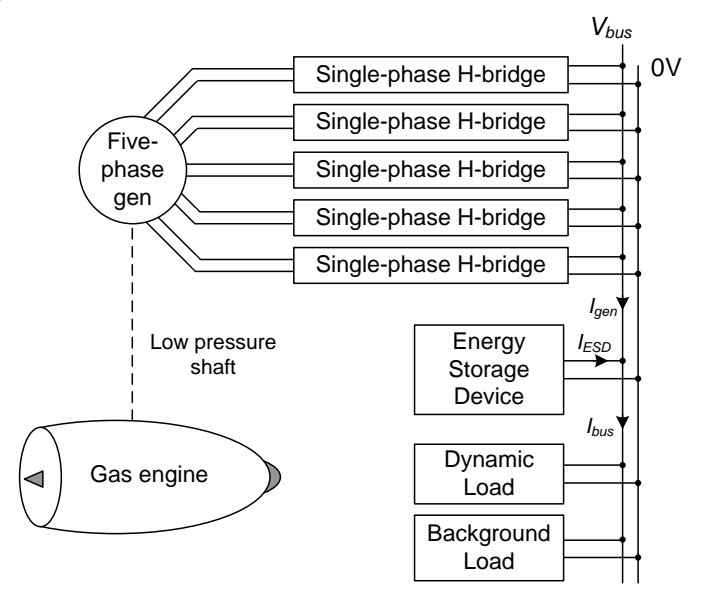

Figure 1. Basic system configuration

The variable amplitude/frequency outputs of the separate five generator phases are connected to the DC distribution bus through single-phase, H-bridge active rectifiers. The generator used in this work is rated at $70 \mathrm{~kW}$ and the DC bus voltage is regulated to be nominally $540 \mathrm{~V}$ by the generator 
control unit. Due to reliability concerns, non-electrolytic capacitors are used for the DC output of the generator system resulting in a relatively small output capacitor value, making the dynamic regulation of the DC bus voltage more difficult.

The ESD in this work is designed to meet instantaneous load transients on the DC bus thereby limiting the rate-ofchange of torque applied by the generator on the gas turbine. The control system for the ESD must satisfy two opposing requirements: track the load changes sinking/sourcing a compensating current to/from the DC bus, and secondly manage the supercapacitor state-of-charge. A power-based control method is proposed to fulfil the two requirements and its performance is assessed using typical avionic load profiles.

In the following sections the ESD is described along with the supercapacitor model and an averaged-value model of the DC/DC converter. The control structure is then explained followed by simulation and experimental results. In the experimental work the ESD is emulated using a bi-directional electronic load and a real-time simulator.

\section{ENERGY STORAGE DEVICE MODELLING}

The ESD, Fig. 2, comprises the supercapacitor bank and the DC/DC converter.

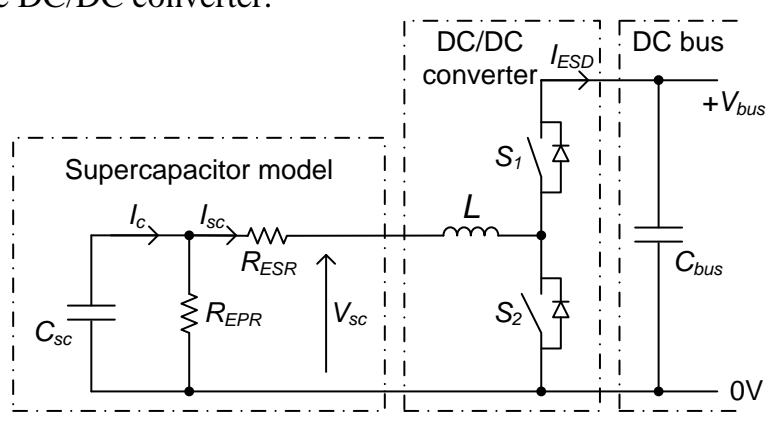

Figure 2. Energy storage device (ESD)

\section{A. Supercapacitors}

An equivalent electric circuit model [2] is used for the supercapacitor bank, shown in Fig. 2, as it provides a good compromise between complexity, accuracy and simulation time for system level studies [3].

The variable $V_{s c}$ is the overall terminal voltage on the supercapacitor bank, $I_{c}$, is the current flowing in the ideal supercapacitor module, and $I_{S c}$ is the terminal current. $R_{E S R}$ and $R_{E P R}$ represent the series resistance and leakage losses. The overall terminal voltage of the supercapacitor bank, $V_{s c}$, is given by (1).

$$
V_{s c}=V_{s c 0}-\frac{1}{C_{s c}} \int I_{c} d t-R_{E S R} I_{s c}
$$

where $V_{s c 0}$ is the initial voltage on the supercapacitor module.

\section{B. DC/DC Converter}

A simple, unisolated bi-directional DC/DC converter, shown in Fig. 2, is used to interface the variable supercapacitor terminal voltage to the fixed voltage DC bus.
An averaged-value model of the power electronics is used to enable long duration transients to be examined easily.

The switches $S 1$ and $S 2$ operate in a complementary manner with variable duty-ratio; the duty-ratio of $S 2$ is $D$. Assuming ideal switches and lossless operation, the averaged-value differential equations for the converter are:

$$
\begin{gathered}
\dot{I}_{s c}=\frac{V_{s c}}{L}-\frac{V_{b u s}}{L}(1-D) \\
\dot{V}_{b u s}=\frac{I_{E S D}-I_{b u s}+I_{g e n}}{C_{b u s}}
\end{gathered}
$$

where $I_{b u s}$ is the total load current, $I_{g e n}$ is the total generator current, $I_{E S D}$ is the ESD output current, $I_{s c}(1-\mathrm{D})$, and $C_{b u s}$ is the combined filter capacitance on the DC bus.

\section{SYSTEM CONTROLLER}

The cascaded ESD control structure, the multiple inputs used to form the supercapacitor current reference and the overall system design are described in this section.

\section{A. Supercapacitor Current Control}

The closed-loop controller used to regulate the supercapacitor current, $I_{s c}$, is shown in Fig. 3.

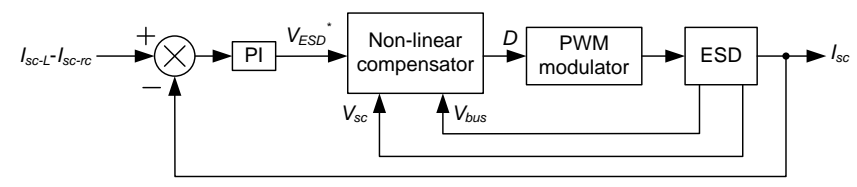

Figure 3. Converter current controller

The output signal from the PI controller, $V_{E S D}{ }^{*}$, is passed through a non-linear compensator to form the transistor duty ratio, $D$. The compensator is designed such that there is a linear, first-order relationship between the control signal, $V_{E S D}{ }^{*}$, and $I_{s c}$. By considering the averaged-value differential equation for the converter inductor current (2) which is equal to $I_{s c}$ the non-linear compensator is determined to be given by:

$$
D=1-\frac{V_{s c}-V_{E S D}^{*}}{V_{b u s}}
$$

The PI controller has a transfer function of the form:

$$
P I(s)=k_{p} \frac{\left(1+T_{I} s\right)}{T_{I} s}
$$

where $T_{I}$ would typically be chosen to place the zero an order of magnitude below the switching frequency.

The maximum and minimum values of $D$ are limited in the PWM modulator to have values of 0.95 and 0.05 respectively.

\section{B. Supercapacitor Current Reference}

The overall reference signal for the supercapacitor current controller has two components, the first $I_{s c-L}$ is determined by the requirement to track the instantaneous load changes on the DC bus, whereas the second, $I_{s c-r c}$, arises from the requirement to manage the supercapacitor state-of-charge. Supercapacitor state-of-charge schemes have been proposed 
in the literature [4-6] for other applications, though these controllers directly define the supercapacitor state-of-charge, whereas the control presented in this section operates indirectly, by means of a droop characteristic; the reference value for the supercapacitor voltage is fixed. The calculation of the two current reference components is shown in Fig. 4.

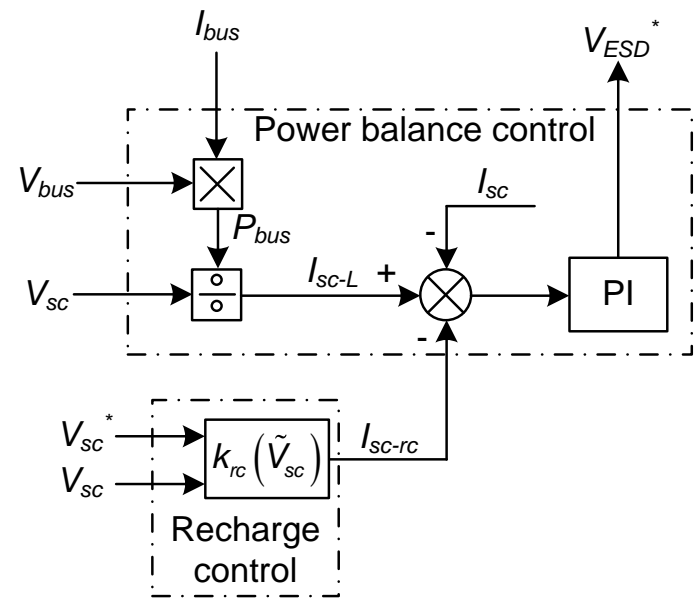

Figure 4. Power-balance and recharge control for ESD

To ensure that the ESD responds rapidly to load changes, $I_{s c-L}$, is determined using an instantaneous power calculation which assumes a lossless DC/DC converter [7]; the instantaneous bus power, $V_{\text {bus }} I_{\text {bus }}$, is divided by the instantaneous supercapacitor voltage, $V_{s c}$, to give $I_{s c-L}$.

The signal $I_{s c-r c}$ controls the rate at which the supercapacitor is recharged and is based on the error, $\tilde{V}_{s c}$, between $V_{s c}$ and the set-point voltage, $V_{s c}{ }^{*}$. Due to the size of the supercapacitors the $I_{s c-r c}$ signal tends to change much more slowly than the $I_{s c-L}$ signal.

The recharge control function, $k_{r c}$, must be chosen to satisfy the conflicting requirements of maintaining the supercapacitor voltage within an acceptable working range whilst limiting the maximum rate-of-change of load that is experienced by the generator.

Due to the operation of the PI controller, under steady-state conditions the two components of the reference for the supercapacitor current, $I_{s c-r c}$ and $I_{s c-L}$, will be equal, that is

$$
k_{r c}\left(\tilde{V}_{s c}\right)=\frac{V_{b u s} I_{b u s}}{V_{s c}}
$$

As a result the steady-state supercapacitor voltage will tend to drop with increased levels of DC bus power, thereby increasing the capability of the supercapacitor bank to absorb energy transiently when there is a sudden reduction of power on the DC bus.

The $k_{r c}$ function could be a simple linear function as has been described in [8], however the use of a non-linear function was found in this work to offer greater flexibility over limiting the generator load transients whilst maintaining the supercapacitor voltage within acceptable limits. A simple non-linear function is described in the following section.

\section{System Design}

To demonstrate the system operation the ESD was designed to compensate the load power drawn by typical radar equipment used for remote sensing and mapping. The load profile is shown in Fig. 5 and comprises a relatively low quiescent power, $4 \mathrm{~kW}$, with a superimposed transient profile comprising an additional $1 \mathrm{~kW}$ load for $25 \mathrm{~s}$ in mode 1 , then a $17 \mathrm{~kW}$ load for $20 \mathrm{~s}$ in mode 2 and $3 \mathrm{~kW}$ for $50 \mathrm{~s}$ in mode 3.

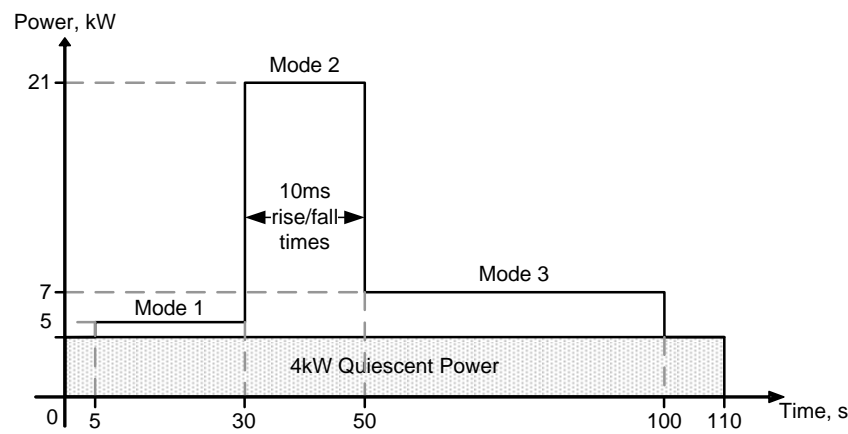

Figure 5. Hypothetical model of a multi-functional radar

A $55 \mathrm{~F}, 145 \mathrm{~V}$ supercapacitor bank was selected, providing a usable energy storage capacity of approximately $0.4 \mathrm{MJ}$.

$R_{E S R}$ and $R_{E P R}$ were $7.1 \mathrm{~m} \Omega$ and $10 \mathrm{k} \Omega$ respectively [9]. The bi-directional DC/DC converter was chosen to have a switching frequency of $30 \mathrm{kHz}$ and an inductor value of $100 \mu \mathrm{H}$. The current control loop bandwidth was $8 \mathrm{kHz}$. The total capacitance on the $540 \mathrm{~V}$ DC distribution bus was $800 \mu \mathrm{F}$.

To maintain the supercapacitor voltage within its working range whilst limiting the maximum rate of change of load applied to the generator shaft, a non-linear function was chosen for the recharge control loop in which

$$
k_{r c}=0.64 \tilde{V}_{s c}^{1.5}
$$

The function, (7), was selected to give a drop in the steadystate supercapacitor voltage of $75 \mathrm{~V}$ corresponding to a load power of $25 \mathrm{~kW}$ as shown in Fig. 6 . If the gain or exponential terms in (7) are reduced then the ESD recharge rate is insufficient for the load profile, Fig. 5. Higher gain or exponential terms in (7) results in larger deviations in DC bus voltage during load transients.

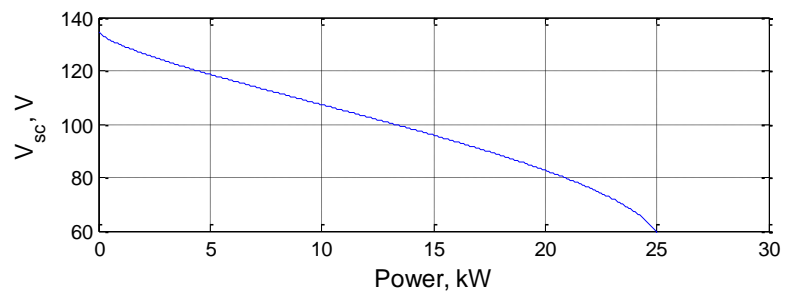

Figure 6. Supercapacitor voltage droop characteristic

The reference supercapacitor voltage, $V_{s c}{ }^{*}$, was set to $135 \mathrm{~V}$. 


\section{V.EXPERIMENTAL TEST SYSTEM}

The laboratory system is shown in Fig. 7 and comprises a $70 \mathrm{~kW}$, five-phase generator and two programmable, $30 \mathrm{~kW}$, bi-directional electronic load units [10]. The generator speed was 1006rpm throughout the tests.

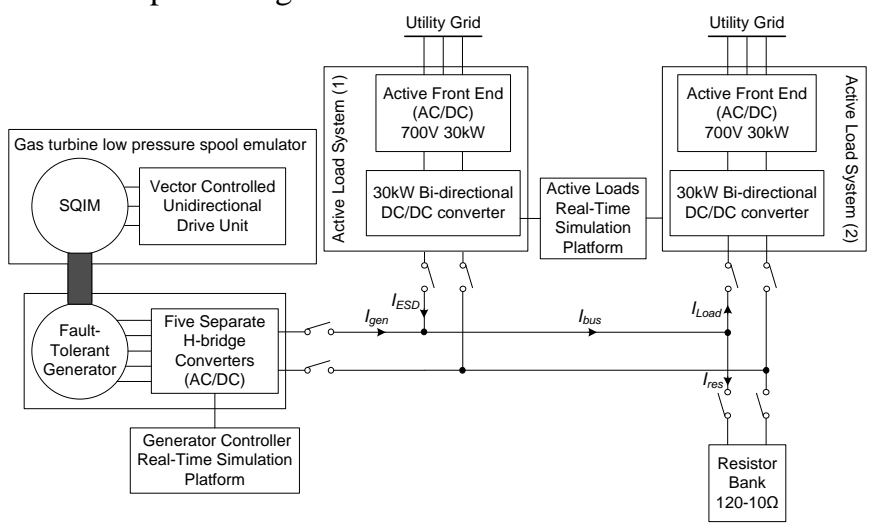

Figure 7. Test set-up

The structure of the programmable active load systems (ALSs) is shown in Fig. 7; a high-bandwidth bi-directional converter operating under the control of a real-time simulation system draws/delivers power from/to the high voltage DC bus and the power is re-generated to/sourced from the utility using a PWM converter.

Active load system ALS(1) was used to emulate the ESD whilst active load ALS(2) was programmed to follow the power steps of the load profile, Fig. 5.

In these proof of principle experiments the measurement of $I_{\text {bus }}$ did not include the current in the resistor bank in Fig. 7 and is referred to as $I_{\text {Load }}$.

\section{EXPERIMENTAL VALIDATION}

A Simulink-based average-value simulation of the entire system has been used to assist in the controller design. Results from the simulation are included in this section along with experimental results. In the experimental system an averaged-value model of the ESD was used to enable longduration power profiles to be examined without compromising the $100 \mathrm{kHz}$ sample rate of the real-time platform.

\section{A. Load Profile with ESD Inactive}

Fig. 8 shows the response of the generator to the load profile, Fig. 5, when the ESD is offline. Measured test data and simulation results are overlaid to demonstrate the close match between the data sets. Large deviations are apparent in the DC bus voltage, $V_{b u s}$, when the load power changes, the voltage reaches a minimum of $189 \mathrm{~V}$ at $\mathrm{t}=30 \mathrm{~s}$ when the power increases from $5 \mathrm{~kW}$ to $21 \mathrm{~kW}$ and a maximum of $680 \mathrm{~V}$ at $\mathrm{t}=50 \mathrm{~s}$ when power drops to $7 \mathrm{~kW}$ from $21 \mathrm{~kW}$. These large bus voltage deviations of over $100 \mathrm{~V}$ are due to the small size of the bus capacitors [11]. At $t=50 \mathrm{~s}$ the high voltage transient on the DC bus caused the active load unit to trip out and is the reason for the discrepancy between the simulation model and measured data beyond $\mathrm{t}=50 \mathrm{~s}$. The measured voltage is seen decaying towards zero, however the generator remained online.

As the generator is the only power source available on the bus, the generator torque, $T_{e}$, bottom plot in Fig. 8, varies directly with the load profile, Fig. 5. This torque variation would be transmitted directly to the gas-turbine in an aircraft system. The severe rates-of-change of torque could compromise the engine operation or trigger mechanical resonances. The measured torque is slightly larger than the simulation value due to losses in the practical system that were not included in the simulation model.
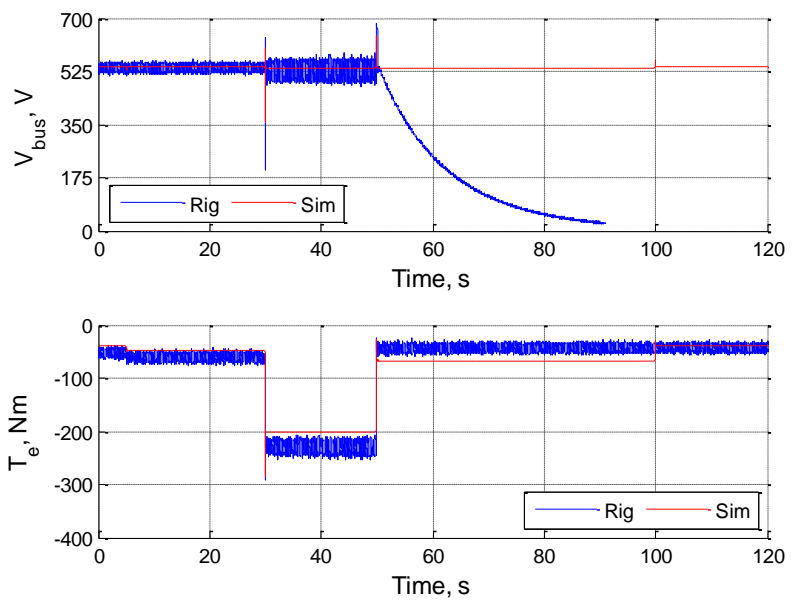

Figure 8. Generator response due to load profile with ESD inactive

\section{B. Load Profile with ESD Active}

Fig. 9 shows the system response to the load profile, Fig. 5, when the ESD is active and the recharge function detailed in section IV.C, (7), is used. An extremely good correlation is evident between the measured test data and the simulation data.

The first and second plots in Fig. 9 show bus voltage, $V_{\text {bus }}$, and generator torque, $T_{e}$. The large deviations apparent in $V_{b u s}$ in Fig. 8 have been virtually eliminated in Fig. 9 by the use of the ESD. $T_{e}$, the second plot in Fig. 9, also shows a much more limited rate-of-change in response to the load transients, when compared to Fig. 8. The more gradual torque changes on the generator shaft are the result of the variable $k_{r c}$ function which enables a slow ESD response to small power steps at low power, $\mathrm{t}=5 \mathrm{~s}$ and $100 \mathrm{~s}$, but clearly enables a fast ESD response to large steps in power, $t=30 \mathrm{~s}$ and 50s. The load current, $I_{\text {Load }}$, and the ESD output current, $I_{E S D}$, are shown in the third plot in Fig. 9. $I_{E S D}$ responds instantaneously to the load changes in an equal but opposite manner, then tends to fall to zero in about 20 or 30 s after the load transient, thereby smoothing the load changes on the generator.

The fourth and fifth plots, in Fig. 9, show the supercapacitor voltage and current, $V_{s c}$ and $I_{s c} . V_{s c}$ is seen to reach its lowest value of just below $100 \mathrm{~V}$ at the end of the high power pulse. Furthermore the voltage level at which $V_{s c}$ tends to settle after a load transient is seen to depend on the load power. During strip mode 2, $50<\mathrm{t}<100$ s, the load power 
from $\operatorname{ALS}(2)$ is $18.6 \mathrm{~kW}$ (in parallel with a $2.4 \mathrm{~kW}$ resistive load) and as predicted by Fig. $6, V_{s c}$ tends to settle at $86.8 \mathrm{~V}$. The reduction in load power at $\mathrm{t}=50 \mathrm{~s}$ and $100 \mathrm{~s}$ results in the ESD absorbing power and so recharging the supercapacitors at differing rates due to the variable $k_{r c}$ function.
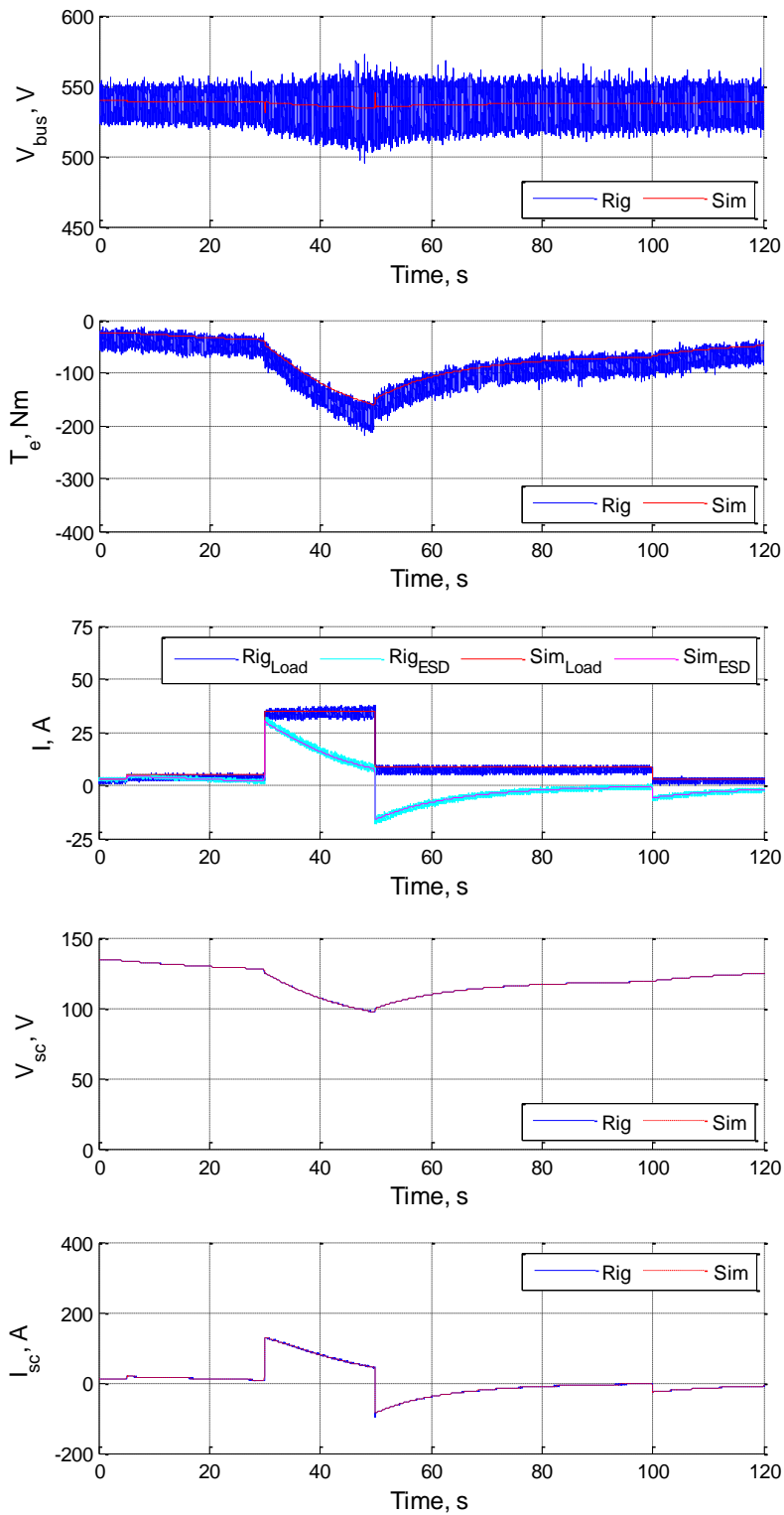

Figure 9. Overall system response due to load profile with ESD active and variable gain recharge

\section{High Frequency Load ESD Inactive}

To examine the performance of the system to higher frequency load changes, the response is considered to a load that switches between $23 \mathrm{~kW}$ and $32 \mathrm{~kW}$, using $\operatorname{ALS}(2)$, with a 0.5 duty-ratio at $0.5 \mathrm{~Hz}$.

Fig. 10 shows the system response of the simulation and test-rig with only the generator active; no ESD. Severe deviations are evident in $V_{\text {bus }}$ (upper waveform Fig. 10) with a minimum of $440 \mathrm{~V}$ when the load increases, $\mathrm{t}=1 \mathrm{~s}, 3 \mathrm{~s}$, and a maximum of $612 \mathrm{~V}$ for the step down in load, $\mathrm{t}=0 \mathrm{~s}, 2 \mathrm{~s}$; the recovery time of $V_{b u s}$ is less than $0.1 \mathrm{~s}$ for either transient. The varying load profile is reflected in $T_{e}$ (lower waveform in Fig. 10) and presents an $85 \mathrm{Nm}$ torque step which may affect the gas turbine. The comparison between simulation and test-rig data shows an excellent correlation for $V_{b u s}$ and a slight difference, due to the omission of losses from the simulation model, in $T_{e}$.
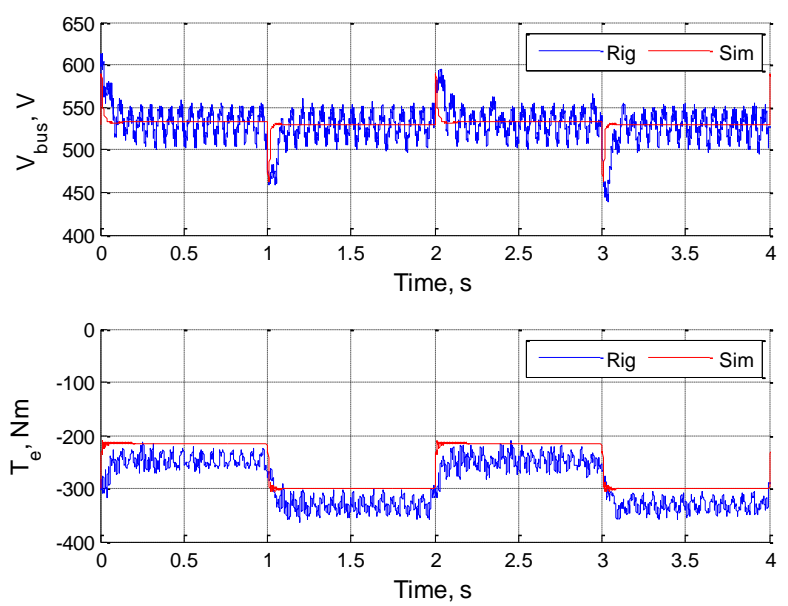

Figure 10. Generator response due to high frequency load with ESD inactive

\section{High Frequency Load ESD Active}

Fig. 11 shows the system behaviour in response to the high-frequency load, as used in Fig. 10, with the ESD active. The deviations in $V_{\text {bus }}$ (top waveform Fig. 11) are almost eliminated at the load steps when compared to Fig 10. $T_{e}$ (second waveform in Fig. 11) exhibits a very mild $6 \mathrm{Nm}$ variation during the $2 \mathrm{~s}$ pulse cycle compared with the abrupt change in Fig. 10. Again, the error between the simulated and measured torque is due to mechanical losses being neglected in the simulation model.

The third set of waveforms in Fig. 11 show $I_{E S D}$ closely following the variation in $I_{\text {Load }}$, and there are corresponding variations in the supercapacitor voltage, $V_{s c}$, fourth plot and supercapacitor current, $I_{s c}$, fifth plot. The step changes in $V_{s c}$ are due to the equivalent series resistance of the supercapacitors, $R_{E S R}$. It is evident from the waveforms that the system has not quite reached steady-state and the supercapacitor voltage is drifting down to a steady-state value of $117 \mathrm{~V}$ as dictated by the droop profile in Fig. 6 . 

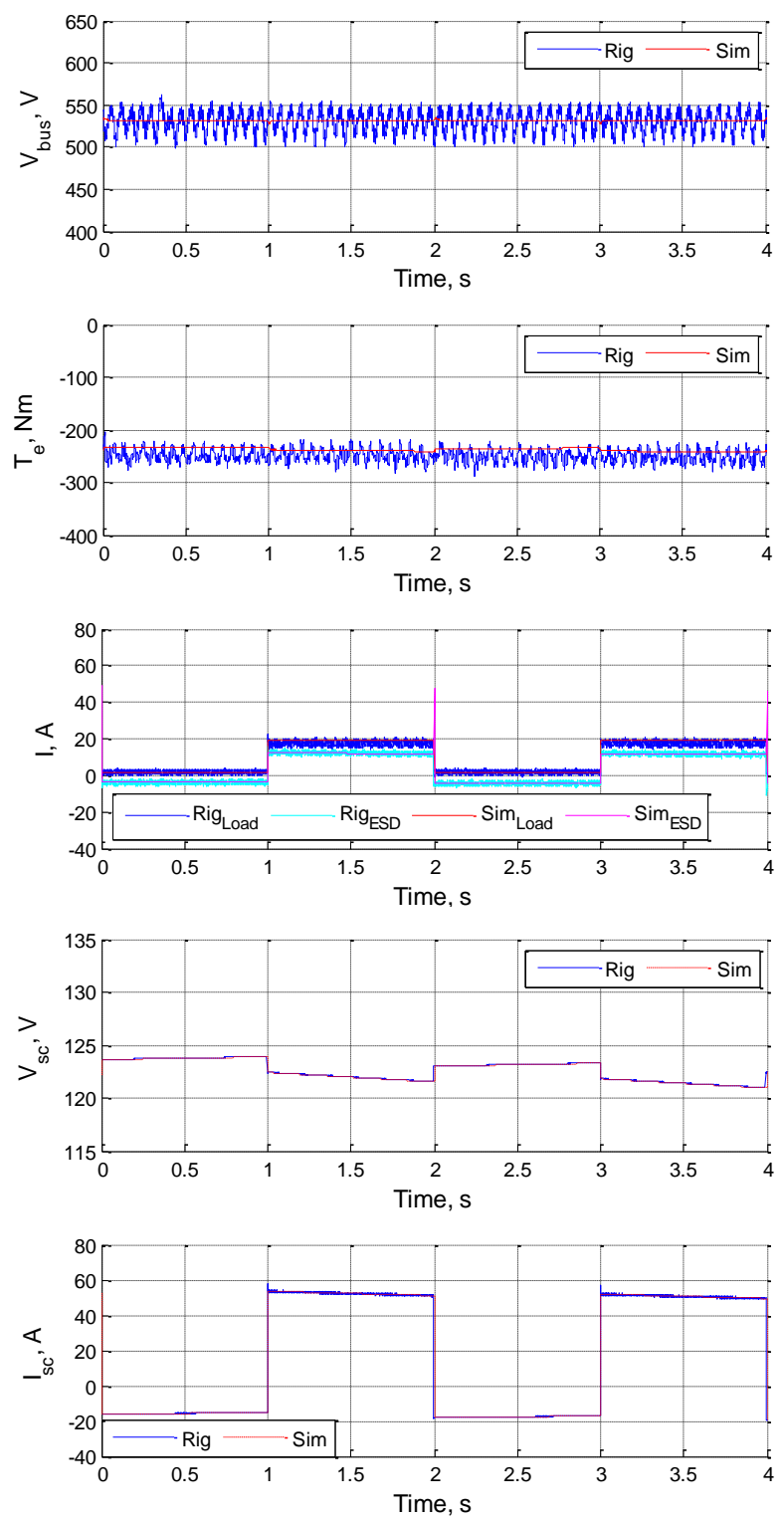

Figure 11. Overall system response due to high frequency load with ESD active and variable gain recharge

\section{E. Load Profile ESD Failure}

The hardware-in-the-loop emulation of the ESD described in this paper enables the system behaviour to be examined over a wide range of conditions and parameters including abnormal operation and failure. This allows the limitations of the device to be established without risking damage to the supercapacitors or transistors.

Fig. 12 shows an example case where the recharge control of the ESD is just a proportional gain of 0.5 , which, as is shown in Fig. 12, is insufficient to maintain the supercapacitor voltage within the working range. As a result of the low value of gain in the recharge controller, the waveforms in Fig. 12 show the ESD current following load current more closely than in Fig. 9 (third plot), the variation in generator torque is more limited than in Fig. 9 (second plot), however the increased energy taken from the supercapacitor results in $V_{s c}$ falling to unacceptably low levels (fourth plot), whilst the supercapacitor current becomes excessively large (fifth plot). At $\mathrm{t}=67 \mathrm{~s}$ the system fails since the supercapacitor voltage is too low to step up to $V_{b u s}$ and the ESD trips out. The generator must then provide the entire load power.

The correlation between the test-rig and simulation data for all variables shown in Fig. 12 is again very good, further confirming the accuracy of the technique.
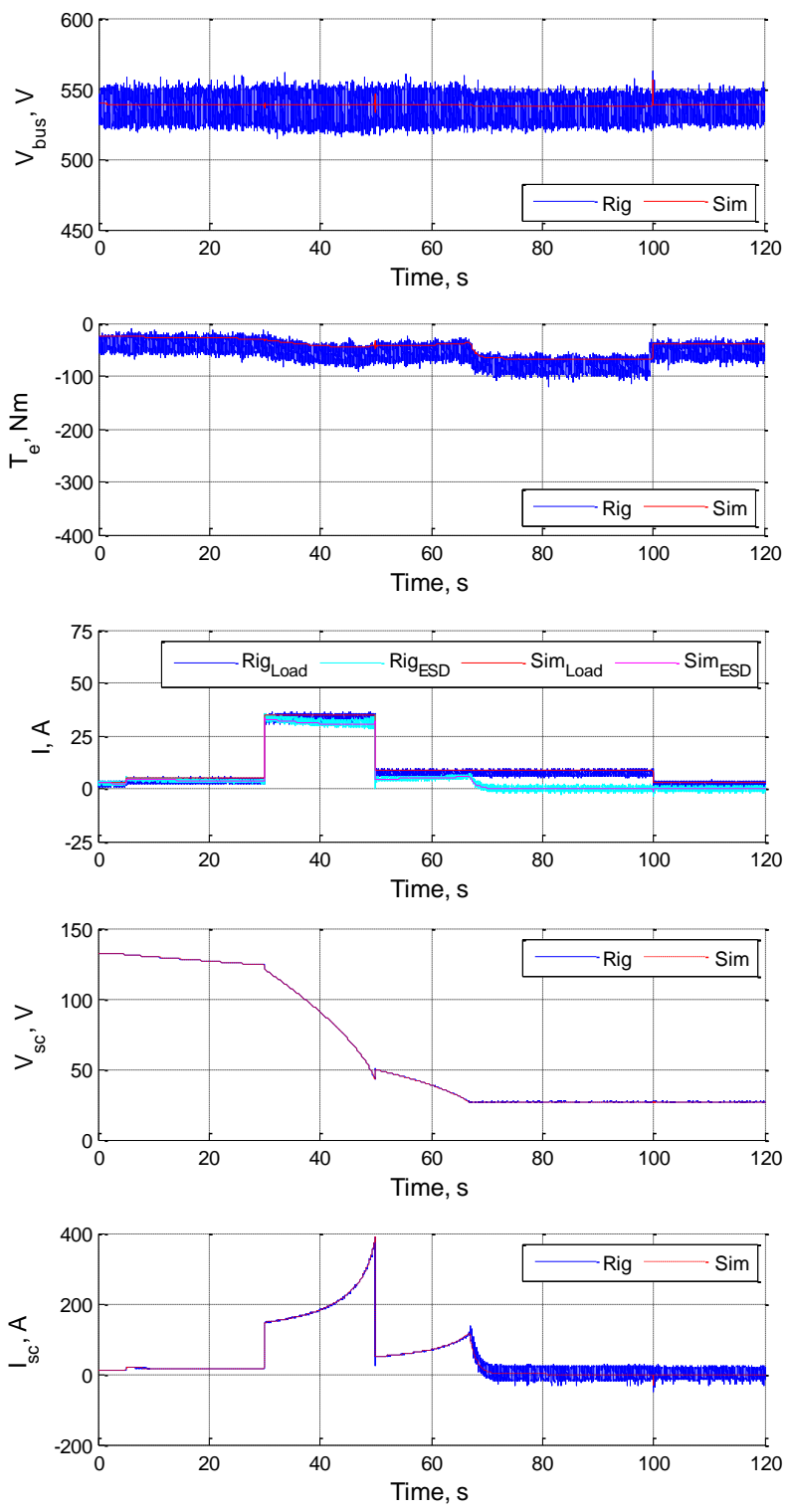

Figure 12. Overall system response due to load profile with ESD active and $k_{r c}=0.5$

\section{CONCLUSIONS}

A power-based method has been shown to provide effective control of a supercapacitor-based energy storage device operating on a high voltage DC bus. The energy storage device responds instantaneously to load changes, 
protecting the engine-driven generator from sudden transients, and virtually eliminating voltage transients from the DC bus. A slower-acting control loop manages the supercapacitor state-of-charge, ensuring that the voltage remains within the working range, but dropping at higher steady-state load powers to enable the energy storage device to absorb energy from the DC bus in the event of a sudden load reduction. A typical radar profile and a higher frequency switching load were used to demonstrate the system performance.

A hardware-in-the-loop technique was used successfully to study the system level performance of the energy storage device whereby a bi-directional load unit operating under the control of a real-time simulation platform emulated the energy storage device, allowing the effects of parameter changes to be readily examined.

\section{REFERENCES}

[1] A. J. Mitcham and J. J. A. Cullen, "Permanent Magnet Generator Options for the More Electric Aircraft," in International Conference on (Conf. Publ. No. 487) Power Electronics, Machines and Drives (PEMD), 2002, pp. 241-245.

[2] R. L. Spyker and R. M. Nelms, "Classical Equivalent Circuit Parameters for a Double-Layer Capacitor," IEEE Transactions on Aerospace and Electronic Systems, vol. 36, pp. 829-836, 2000.

[3] M. Uzunoglu and M. S. Alam, "Dynamic Modeling, Design, and Simulation of a Combined PEM Fuel Cell and Ultracapacitor System for Stand-Alone Residential Applications," IEEE Transactions on Energy Conversion, vol. 21, pp. 767-775, 2006.

[4] E. Schaltz, A. Khaligh, and P. O. Rasmussen, "Influence of Battery/Ultracapacitor Energy-Storage Sizing on Battery Lifetime in a Fuel Cell Hybrid Electric Vehicle," IEEE Transactions on Vehicular Technology, vol. 58, pp. 3882-3891, 2009.

[5] P. Thounthong, P. Sethakul, S. Rael, and B. Davat, "Performance Investigation of Fuel Cell/Battery and Fuel Cell/Supercapacitor Hybrid Sources for Electric Vehicle Applications," in 4th IET Conference on Power Electronics, Machines and Drives (PEMD), 2008, pp. 455-459.

[6] J. Dixon, M. Ortúzar, and E. Wiechmann, "Regenerative Braking for an Electric Vehicle using Ultracapacitors and a Buck-Boost Converter," in Proc. 17th Int. Electr. Vehicle Symp., Montreal, QC, Canada, CDROM, Oct. 13-18, 2000.

[7] B. J. Arnet and L. P. Haines, "High Power DC-to-DC Converter for Supercapacitors," in IEEE International Electric Machines and Drives Conference (IEMDC 2001), 2001, pp. 985-990.

[8] P. Thounthong, V. Chunkag, P. Sethakul, B. Davat, and M. Hinaje, "Comparative Study of Fuel-Cell Vehicle Hybridization with Battery or Supercapacitor Storage Device," IEEE Transactions on Vehicular Technology, vol. 58, pp. 3892-3904, 2009.

[9] Maxwell Technologies, "Maxwell Technologies BMOD0083-48.6V Ultracapacitors." vol. 2009: http://www.maxwell.com/ultracapacitors/ products/modules/bmod0083-48-6v.asp, Nov. 2009.

[10] F. J. Chivite-Zabalza, A. J. Forsyth, D. R. Trainer, J. Calvignac, S. Long, and R. Todd, "Control and Development of an Electrical Systems Evaluation Platform for Uninhabited Autonomous Vehicles," in 34th Annual Conference of IEEE Industrial Electronics (IECON), 2008, pp. 1479-1486.

[11] R. Todd, A. A. Abd Hafez, A. J. Forsyth, and S. A. Long, "Single-Phase Controller Design for a Fault-Tolerant Permanent Magnet Generator," in IEEE Vehicle Power and Propulsion Conference (VPPC), 2008, pp. 1-6. 